\title{
MACHADO DE ASSIS: \\ IRONIA E FILIAÇÃO LITERÁRIA
}

\section{MACHADO DE ASSIS: IRONY AND LITERARY FILIATION}

\author{
Andrea Czarnobay Perrot*
}

RESUMO: A crítica costumeiramente caracterizou a ironia machadiana como um traço da personalidade do autor e não como um procedimento de construção literária. Nesse caso, o limite entre narrador e autor parece não existir. A partir dessa abordagem, traçamos uma espécie de painel a respeito da presença e do significado da ironia na obra de Machado de Assis, bem como dos aspectos que concernem a sua filiação literária.

PALAVRAS-CHAVE: Machado de Assis, ironia, filiação literária.

ABSTRACT: The literary critics usually characterized the "ironia machadiana" as a trace of the author's personality, instead of a procedure of literary construction. In this case, the limit between the narrator and the author seem not to exist. From this approach, we sketch a panorama regarding the presence and the meaning of the irony in the works of Machado de Assis, as well of the aspects that concerns his literary filiation.

KEY WORDS: Machado de Assis, irony, literary filiation.

* Doutora em Letras pela Universidade Federal do Rio Grande do Sul. Professora do curso de extensão em Leitura e Produção Textual do NELE/ UFRGS e revisora da ediotora ARTMED/BDKmann. 



\section{A obra de Machado de Assis na historiografia da literatura brasileira}

\subsection{José Veríssimo (1916)}

Em 1916 é publicada História da Literatura Brasileira, de José Veríssimo. Em capítulo dedicado unicamente a Machado de Assis (Cap. XIX), a respeito de sua filiação a escolas literárias o pesquisador afirma:

A data do seu nascimento e do seu aparecimento na literatura o fazem da última geração romântica. Mas a sua índole literária avessa a escolas, a sua singular personalidade, que lhe não consentiu jamais matricular-se em alguma, quase desde os seus princípios fizeram dele um escritor à parte, que tendo atravessado vários momentos e correntes literários, a nenhuma realmente aderiu senão mui parcialmente, guardando sempre a sua isenção. (1981, p. 415).

Apesar de distante no tempo, compartilhamos da opinião de Veríssimo, uma vez que defendemos o "enquadramento" da obra de Machado de Assis numa espécie de entre-lugar - lugar esse ocupado pelo Romantismo, pelo Realismo e, principalmente, pela Modernidade literária.

Note-se, ainda, como em outros críticos contemporâneos seus, a linha biografista de José Veríssimo, mesclando elementos literários com dados pessoais do autor para justificar, primeiramente, o humor de sua obra: 
Entrementes aprendera o inglês, língua pouco vulgar aos nossos literatos e cuja literatura não teria concorrido pouco para ajudar a tendência natural de Machado de Assis ao humor, de que foi aqui o único mestre insigne. Também lhe daria o esquisito sentimento de decoro que distingue a sua obra, e o defendeu das influências do naturalismo francês. (1981, p. 417).

Sobre a ironia, diz Veríssimo:

Havia entretanto no primeiro romance de Machado de Assis e ainda mais talvez nos que mais de perto o seguiram, A mão e a luva (1874), Helena (1876), visíveis ressaibos de romantismo senão do Romantismo. Temperava-os, porém, já, diluindo-os num sabor mais pessoal e menos de escola, a sua nativa ironia e a sua desabusada visão das cousas, que o forravam ao romanesco, à sentimentalidade amaneirada que tanto viciou e desluziu a nossa ficção. (1981, p. 428).

A ironia machadiana é considerada pelo crítico como o "algo mais" que distinguia a literatura de Machado de Assis da literatura romântica brasileira do mesmo período. Concordamos novamente com o autor - embora, hoje, devido ao instrumental teórico mais apropriado que possuímos há tempos estabelecido na crítica literária -, a não ser por um aspecto: a ironia de que fala Veríssimo também é parte do movimento romântico, também é um procedimento estruturante surgido e implementado pelo Romantismo - no sentido europeu do termo, vale ressaltar. Tal constatação leva-nos a considerar que mesmo a fase dita "madura" de Machado de Assis - realista - emprega um dos principais procedimentos que compuseram a "cartilha" do movimento literáriofilosófico chamado Romantismo, a saber, a ironia literária.

Em Veríssimo, a visão de ironia como algo oposto ao Romantismo é reforçada na seguinte passagem:

Histórias da meia-noite (1870) e Contos fluminenses (1873), traziam ressaibos românticos, embora atenuados pelo congênito pessimismo e nativa ironia do autor. Ora o Romantismo não comportava nem a ironia nem o pessimismo, na forma desenganada, risonha e resignada de Machado de Assis. Mas os contos que sucederam imediatamente àqueles, Papéis avulsos (1882), Histórias sem data (1884), Várias histórias (1905), muitos deles anteriores a Brás Cubas, trazem já evidente o tom deste. Desde, portanto, os anos de 70, renunciando ao 
escasso Romantismo que nele havia, criava-se Machado de Assis uma maneira nova, muito sua, muito particular e muito distinta e por igual estreme daquela escola e das novas modas literárias. (1981, p. 429-430).

Nesta passagem, encontramos o que são, para nós, dois equívocos presentes na maioria da fortuna crítica acerca da obra de Machado de Assis, e um grande acerto. Os equívocos são: 1) considerar a ironia como algo completamente dissociado, e, por vezes, oposto, ao Romantismo enquanto escola literária; 2) considerar a ironia machadiana não como um procedimento estruturante de um texto, mas, sim, como uma espécie de atitude do homem Machado de Assis frente à vida (o que é reforçado pelo emprego das palavras congênito e nativa, referentes, respectivamente, ao pessimismo e à ironia). $\mathrm{O}$ acerto reside na consideração de que Machado negava, com sua peculiar escrita, tanto o rótulo da escola que o precedeu - Romantismo -, quanto o da escola que lhe sucedeu - Realismo -, embora, para isto, tenha utilizado e adaptado ao seu fazer literário elementos de ambas correntes.

\subsection{Nélson Werneck Sodré (1938)}

Em 1938, sai a primeira edição de sua História da Literatura Brasileira. Em capítulo intitulado "Interpretação do Brasil", o autor aborda a ficção de Machado de Assis, mais especificamente, a questão da filiação literária de sua obra. No trecho a seguir, comenta-se a influência romântica na literatura machadiana: "Machado de Assis é a grande figura literária do tempo e a maior que nosso país conheceu. Vem do romantismo e recebe da escola, na primeira fase de sua obra, os elementos da técnica e do conteúdo". (2002, p. 551).

Fica implícito, aqui, a utilização do procedimento irônico como elemento da técnica herdado dos românticos? Esta é nossa opinião, mas pode não ser, com absoluta certeza, a opinião de Sodré. Vejamos mais um trecho:

Sua carreira literária tem duas fases bem nítidas, a primeira, em que é ainda romântico, embora anunciando, aqui e ali, a posse daquelas virtudes que se engrandecerão na segunda. Depois, e com intervalo curto, evolui para uma posição realista inequívoca, embora não ligada à forma de expressão que o realismo assumiu com a escola naturalista, que teve o senso de desprezar. (2002, p. 557) 
Como todos os críticos da época, Sodré considera a "fase romântica" machadiana como menor em relação à "fase realista". O importante, em relação á filiação literária da obra de Machado de Assis, é verificar que um dos procedimentos mais utilizados pelo escritor na sua fase dita "madura" (e, portanto, digna da grandeza do escritor, em detrimento da fase romântica), já se encontrava, porém menos intensamente, na dita fase "inicial".

A ironia foi alçada ao status de elemento da configuração literária (e não, somente como parte da retórica), justamente no período romântico europeu, período em que surgiram mestres da literatura universal exemplares pra Machado.

\subsection{Lúcia Miguel-Pereira (1950)}

Em 1950 é publicada História da Literatura Brasileira - Prosa de Ficção (de 1870 a 1920), obra que, em capítulo intitulado "Pesquisas Psicológicas", avalia o valor e a representatividade da literatura machadiana no cenário artístico nacional. Para Lúcia, Memórias Póstumas é o divisor de águas de toda a literatura brasileira, e não, apenas da obra machadiana, visto que ela já identifica, nos chamados romances da primeira fase - "românticos" -, traços da investigação psicológica que caracterizaria a radical mudança preconizada por Machado de Assis nos rumos de nossa literatura. A autora ainda afirma existir em Machado uma negação de vários dos aspectos marcantes da poética romântica, já nos romances da dita primeira fase de sua literatura:

Mesmo em seus primeiros livros, quando ainda o cerceavam os cânones românticos e possivelmente o inibia a timidez, o receio de ser diferente dos outros, de enveredar por caminhos até então indevassáveis, já as suas figuras se distinguem pela independência em relação ao meio físico e ao moralismo convencional. Não obedeceu nem ao preconceito, então de rigor, de filiar à natureza tropical o feitio das criaturas, nem ao de fazer personagens exclusivamente boas ou más, tão caro ao romantismo. (1950, p. 58).

Fica assim demonstrada pela autora a inadequação da filiação da obra de Machado de Assis a uma ou outra escola, sendo ela emblemática de uma nova literatura, de uma nova feição literária, a nosso ver, representada pela utilização do procedimento irônico forjado no romantismo europeu, procedimento estruturador de um texto, alçado ao status de princípio estilístico. 
A despeito disso, identificam-se alguns traços românticos em sua obra, porém transformados no momento em que entram em contato com o fazer literário de Machado: "Era um romantismo mitigado e estranhamente modificado, o seu. Romantismo e contenção são termos que se repelem, e Machado de Assis foi, antes de tudo, um homem contido, medido e comedido". (1950, p. 62).

Adiante em sua análise, a autora afirma ter sido Machado muito mais realista do que romântico, e assim o justifica:

Sem preocupação de escola literária desde que se libertou do romantismo, ele observou, como ninguém entre nós, as criaturas em toda a sua realidade, dando a cada aspecto o justo valor, isto é, apreciando a todos com um critério relativo. Foi assim que esse tímido realizou uma audaciosa revolução na nossa literatura ficcionista, até ele subordinada a valores absolutos, que reduziam a simples figurantes as personagens dominadas pela natureza e pela ética convencional. (1950, p. 72).

Quanto à presença da ironia, Lúcia pratica a crítica biográfica mais comum em relação a esta característica da poética machadiana: ela fala da ironia da vida e do homem irônico, e não, da ironia como elemento estruturante do texto literário machadiano, o que nos parece um equívoco, pois tal crítica perde de vista o aspecto estético da literatura para se calcar na figura, no homem Machado de Assis: "No fundo, a mestra da ironia desse perscrutador de vilanias foi a vida, cujas lições em parte adoçou por lhe parecer que a grande culpada era ela”. (1950, p. 94).

\subsection{Afrânio Coutinho (1969)}

Em trabalho intitulado A literatura no Brasil (1969), Coutinho dedica um capítulo inteiro a Machado de Assis, inserido no volume 3 da coleção. Não fugindo à regra, o crítico faz menção à questão da filiação literária de Machado no seguinte trecho:

A sua importância, na vida intelectual brasileira, não encontra paralelo, pela qualidade e abundância da obra e pelo caráter inconfundível do escritor, que atravessou incólume todos os movimentos e escolas, constituindo um mundo à parte, um estilo composto de técnicas precisas e eficazes, e uma galeria de tipos absolutamente realizados e convincentes. (1969, p. 135). 
Temos aqui a recorrente supressão dos limites entre autor e indivíduo, quando Coutinho afirma ser o "caráter inconfundível do escritor" um dos elementos responsáveis pela importância de sua obra na literatura brasileira. Por outro lado, o crítico acerta quando afirma que Machado de Assis "atravessou incólume todos os movimentos e escolas", indo ao encontro do ponto de vista defendido neste trabalho, o qual situa a produção literária machadiana numa espécie de entre-lugar, confluência entre Romantismo, Realismo e Modernidade.

Ainda discutindo essa questão, afirma o crítico:

Costuma-se admitir na obra de Machado de Assis a distinção de duas fases [...]. Esse esquema tem a vantagem de assinalar a brusca mutação do romancista, como resultado da crise espiritual dos 40 anos e da ocorrência de grave moléstia que o deslocou para Fribrugo. Seria indiscutível [essa distinção], se não houvesse na fase anterior algumas excelentes produções no gênero do conto e outros modos menores. (1969, p. 137).

A crítica impressionista e biografista desenvolvida à época lançava mão de elementos da vida pessoal do escritor, utilizando-os como justificativas ou causas de seu estilo literário. Há, porém, uma frágil constatação - acertada, diga-se de passagem -, que revela a sensibilidade estética de Coutinho, baseada em análise puramente literária: a divisão da obra machadiana em duas fases distintas "seria indiscutível, se não houvesse na fase anterior algumas excelentes produções no gênero do conto e outros modos menores". Essa afirmativa dá margem à tese desenvolvida aqui, a de que a ironia machadiana é, além de herdada do Romantismo europeu - denotando, portanto, o caráter romântico do fazer literário de Machado de Assis -, elemento presente em todas as fases de sua produção literária, e não, apenas na fase "madura" ou "realista". A crítica machadiana, na maioria dos casos, coloca a ironia como algo externo ao Romantismo, mas já mostramos, em capítulos anteriores, que a ironia literária faz parte não só do Romantismo, mas, também, de todas as escolas e movimentos literários surgidos a partir da modernidade.

Finalmente, referindo-se à presença do humorismo na obra machadiana, afirma Coutinho: "Tempera ainda o Romantismo, desde os primeiros contos, com o neutralizante que tanto utilizou para evitar a ênfase e o transbordamento sentimental - o humorismo" (1969, p. 140). Para o 
crítico, o humorismo machadiano - e certamente a ironia aqui está inclusa, de acordo com padrões teóricos de então -, não passa de um tempero, de um agente neutralizador do exacerbado sentimentalismo característico do romantismo, sendo que a hipótese de que o humorismo é um procedimento formal representante de uma visão de mundo não é sequer cogitada.

\subsection{Alfredo Bosi (1974)}

Em História Concisa da Literatura Brasileira (1974), Alfredo Bosi, a propósito de Memórias Póstumas de Brás Cubas, considerado usualmente o divisor de águas da obra machadiana, classificando-a como romântica (anterior) e realista (posterior), afirma:

A revolução dessa obra, que parece cavar um fosso entre dois mundos, foi uma revolução ideológica e formal: aprofundando o desprezo às idealizações românticas e ferindo no cerne o mito do narrador onisciente, que tudo vê e tudo julga, deixou emergir a consciência nua do indivíduo, fraco e incoerente. $\mathrm{O}$ que restou foram as memórias de um homem igual a tantos outros, o cauto e desfrutador Brás Cubas. (1974, p. 197).

Para ele, as Memórias transgridem tanto a poética romântica quanto a realista, o que sustenta a sua posição de não considerar Machado como "classificável" apenas nesta ou naquela escola literária, uma vez que sua obra transcende ambas as definições, revelando um magistral caráter de independência em relação a movimentos literários definidos a priori. Bosi considera Machado de Assis adepto de um relativismo onipresente; sua filosofia "pessimista" pode, portanto, apresentar-se como um elemento que talvez justifique a recusa de um ou de outro rótulo para sua literatura:

Menos do que 'pessimismo' sistemático, melhor seria ver como suma da filosofia machadiana um sentido agudo do relativo: nada valendo como absoluto, nada merece o empenho do ódio ou do amor. Para a antimetafísica do ceticismo, a moral da indiferença. (1974, p. 203).

\subsection{Antonio Candido (1975)}

Em Formação da Literatura Brasileira (1975), a obra de Machado de Assis é sempre uma referência, sem, entretanto, haver a existência de um capítulo restrito à sua análise. Isto se dá porque o objetivo da obra é realizar uma 
análise das condições e circunstâncias de formação da nossa literatura. Para Candido, Machado surge no cenário literário brasileiro como um dos primeiros autores a usufruir uma literatura brasileira não mais em formação, mas madura e independente. Ele realiza, pois, uma bem-sucedida carreira no circuito literário do Brasil, aproveitando elementos desenvolvidos superficialmente por seus antecessores, principalmente por José de Alencar.

Em relação a isso, e também se referindo à questão da filiação literária da obra machadiana, afirma Candido:

Ele [Machado] pressupõe a existência dos predecessores, e esta é uma das razões da sua grandeza: numa literatura em que, a cada geração, os melhores recomeçam da capo e só os medíocres continuam o passado, ele aplicou o seu gênio em assimilar, aprofundar, fecundar o legado positivo das experiências anteriores. Este é o segredo da sua independência em relação aos contemporâneos europeus, do seu alheamento às modas literárias de Portugal e França. Esta, a razão de não terem muitos críticos sabido onde classificá-lo. (1997, p. 104. Grifos meus).

\subsection{José Guilherme Merquior (1977)}

Em De Anchieta a Euclides - Breve História da Literatura Brasileira, o lugar dado a Machado de Assis em nossas letras é o privilegiado de sempre. Há, porém, algumas idéias novas a respeito de sua obra, principalmente os romances, identificados pelo crítico como romances impressionistas. Encontramos, ao longo do último capítulo - O Segundo Oitocentismo (1877-1902) -, diversas referências às particularidades da prosa e da poesia machadianas, bem como considerações a respeito da filiação da obra literária de Machado de Assis a esta ou aquela escola.

Em relação a esta última questão, dando início às considerações sobre o tema, afirma Merquior: “... mas o grande e originalíssimo representante nacional do espírito e da letra da literatura impressionista é Machado de Assis, um contemporâneo, pelo nascimento, dos ultra-românticos" (1996, p. 208). Ainda seguindo esta linha de pensamento, Merquior considera que Machado de Assis chegou ao impressionismo depois de se ter impregnado de traços românticos na juventude.

Ao referir-se aos primeiros livros de contos de Machado, Contos Fluminenses (1870) e Histórias da Meia-Noite (1873), o crítico afirma: "São anedotas às vezes apressadamente redigidas, às vezes cheias de convenções 
românticas, mas temperadas, sobretudo no último volume, por um humorismo que prenuncia a visão "corrosiva" do Machado maduro" (1996, p. 215). Tal afirmativa interessa-nos, sobretudo, por considerar que já havia, na fase inicial da literatura machadiana, elementos que viriam a ser característicos e fundamentais na obra do Machado maduro, elementos como o humorismo, que, para nós, vem a ser uma faceta da ironia romântica européia, absorvida por Machado de Assis através de suas leituras.

Ainda sobre esta questão, o crítico opina:

A despeito da inegável significação de suas obras de índole romântica (do que se convencionou chamar "primeira fase" de sua produção), Machado de Assis só atingiu a dignidade de figura central das nossas letras após ter superado o romantismo - superação que se perfez em torno de 1878-80. (1996, p. 220).

Merquior concorda, assim, com a maioria da crítica acerca da obra machadiana, considerando a sua fase "romântica" menos importante e significativa que sua fase "realista", sendo a superação do romantismo condição sine qua non para atingir a dignidade de figura central de nossa literatura.

\section{A ironia machadiana:}

\section{uma proposta alternativa de (re)interpretação}

Propomos, baseados principalmente na análise do texto machadiano, que sua ironia, tomada como característica principal da chamada fase "madura" do escritor (ou fase realista) é, na verdade, herdada do movimento romântico europeu. Por isso, está presente em toda a obra machadiana, desde seus primeiros escritos, considerados por muitos como menores, pertencendo a sua fase "inicial", classificada pejorativamente como sendo sua fase romântica.

A "ironia romântica" aparece especificamente, em literatura, como um procedimento através do qual o autor explicita todos os jogos possíveis para dissimular sua intenção verdadeira e para romper a atmosfera de ilusão presente em toda obra de arte. A ironia romântica pode, assim, ser interpretada como um princípio literário estruturante e específico, baseado no jogo entre os sentidos possíveis.

Em Ironie et Modernité (1997), Ernst Behler afirma existir um elo entre a consciência da modernidade literária e a ironia no que diz respeito não só à literatura como manifestação artística, mas, também, à crítica sobre a 
mesma. A partir do elo identificado por Behler, desenvolveremos um trabalho de análise que demonstra ser a ironia de Machado de Assis um dos elementos que permitem filiar sua obra como pertencente ao Romantismo (conseqüentemente, à Modernidade), apontando para que não a consideremos como uma produção artística cindida em duas fases - uma romântica, no sentido mais pejorativo e depreciador dado ao termo, e outra realista, sendo esta considerada a fase onde a maestria literária de Machado de Assis veio a lume.

Situamos a produção literária machadiana neste entre-lugar devido ao emprego da ironia como princípio estilístico ${ }^{1}$, representando sua visão de mundo ${ }^{2}$ perante as questões de seu tempo. Tal emprego da ironia iniciouse, no campo literário, com as estratégias românticas/modernas de autorepresentação da arte e de quebra da aura ilusória da mesma, daí a relação que este trabalho pretende demonstrar existir entre a produção machadiana e o Romantismo.

Sobre a ironia romântica, afirma Irlemar Chiampi:

Friedrich Schlegel é o teórico da "ironia romântica", procedimento que acarreta a quebra da ilusão da realidade e torna transparente o processo de criação da obra, apontando-a como construção artificial, artística. O valor atribuído à reflexão, seja dentro da obra, como "poesia da poesia", seja fora dela, como crítica de arremate, indica claramente que a obra romântica está longe de ser um mero subproduto da subjetividade. (1991, p. 23).

É esse o ponto que desejamos atingir, propondo que se reconheça a existência de procedimentos característicos da literatura romântica na obra machadiana e que são esses os elementos que legitimam o caráter de modernidade que a ela conferimos.

Assim, Machado de Assis, fazendo uso peculiar e característico da ironia, pode ter construído sua obra a partir de uma estratégia surgida no movimento romântico - a ironia "romântica" (de caráter literário) -, através da qual antecipou procedimentos da literatura moderna. Essa hipótese, portanto, torna possível uma revisão no que diz respeito à sua filiação literária,

${ }^{1}$ Procedimento de composição que, além de determinar a estrutura formal da obra, expressa a visão de mundo e a filosofia do autor conforme regras próprias do campo literário.

${ }^{2}$ Determinado conjunto de valores e/ou conceitos que informam a leitura que o autor faz da realidade em que está inserido. 
visto que, ao optar pela utilização do procedimento irônico, Machado realiza sua relação com o Romantismo e com a Modernidade, atestando a feição pioneira de sua literatura, esta sim, a sua mais autêntica característica.

Estaríamos, nesse caso, acrescentando uma proposição diversa à tradicional fortuna crítica machadiana, que o classifica preferencialmente como realista, às vezes ignorando ou, até mesmo, menosprezando a possível presença de estratégias românticas em sua obra.

\section{Alguma exemplificação}

Apresentamos a análise do conto Miss Dollar, publicado no primeiro livro de contos de Machado de Assis, Contos Fluminenses (1870), a fim de exemplificar nossa proposta alternativa de (re)interpretação da filiação literária machadiana e, também, da significação da presença da ironia em sua obra.

O capítulo primeiro de Miss Dollar ${ }^{3}$ - o conto é dividido em 8 capítulos -, é exemplar da estratégia irônica machadiana. Nele, Machado já põe em prática desde o primeiro parágrafo a veia irônica de sua literatura:

Era conveniente ao romance que o leitor ficasse muito tempo sem saber quem era Miss Dollar. Mas por outro lado, sem a apresentação de Miss Dollar, seria o autor obrigado a longas digressões, que encheriam o papel sem adiantar a ação. Não há hesitação possível: vou apresentar-lhes Miss Dollar. (1997, p. 27).

Colocando-se fora das estruturas da ficção, visto que se refere a si mesmo como "o autor", o narrador enceta uma conversa com o leitor a respeito da construção da obra literária. Informa-o de que seria conveniente ao início do texto a apresentação de Miss Dollar, mas comenta que, apesar da conveniência, tal procedimento o faria perder-se em longas digressões, sem importância para o andamento da história narrada. No entanto, é justamente por digressões que o texto prossegue: é a ambigüidade da ironia manifestando-se no texto machadiano.

Logo, apesar da última frase do primeiro parágrafo indicar que Miss Dollar será apresentada em seguida, não é o que se sucede. É a linguagem negando-se a si mesma. Segue-se, assim, um longo trecho onde o narrador

\footnotetext{
3 Todas as citações do conto Miss Dollar foram retiradas de MACHADO DE ASSIS, Joaquim Maria. Obra Completa. Rio de Janeiro: Nova Aguillar, 1997, volume II. Mencionaremos, então, o ano da edição e o número da página.
} 
conjetura sobre a imaginação do leitor, suspendendo a ilusão da obra ficcional devido à entrada do leitor no "jogo" literário:

Se o leitor é rapaz e dado ao gênio melancólico, imagina que Miss Dollar é uma inglesa pálida e delgada.(...) Suponhamos que o leitor não é dado a estes devaneios e melancolias; nesse caso imagina uma Miss Dollar totalmente diferente da outra. Desta vez será uma robusta americana.(...) Já não será do mesmo sentir o leitor que tiver passado a segunda mocidade e vir diante de si uma velhice sem recurso. Para esse, a Miss Dollar verdadeiramente digna de ser contada em algumas páginas seria uma boa inglesa de cinqüenta anos (...). Mais esperto que os outros, acode um leitor dizendo que a heroína do romance não é nem foi inglesa, mas brasileira dos quatro costados, e que o nome Miss Dollar quer dizer simplesmente que a rapariga é rica. (1997, p. 27-28).

A ironia, nesta parte do texto, está presente na intencionalidade implícita: ao invés de caracterizar (apresentar) a personagem-título, o que o narrador faz, na verdade, é tentar caracterizar o leitor. É interessante olhar atentamente, também, para a descrição das mulheres que, supostamente, $o$ leitor imagina serem Miss Dollar. Algumas delas são verdadeiras personagens românticas; outras, personagens típicas da escola realista. Outro dado importante: caracterizando o leitor do conto, o narrador termina por caracterizar diferentes escolas literárias: é o não-dito dizendo mais do que o dito, estratégia irônica genuína.

Ao final das suposições, próximo de revelar quem é realmente Miss Dollar, o narrador assim resume: "A Miss Dollar do romance não é a menina romântica, nem a mulher robusta, nem a velha literata, nem a brasileira rica. Falha desta vez a proverbial perspicácia dos leitores; Miss Dollar é uma cadelinha galga" (1997, p. 28). Uma cadelinha galga, eis o mistério acerca da personagem-título do conto. Supondo diversos tipos de mulher, desde a idealizada jovem, bela e pálida romântica até a genuína brasileira rica, $o$ leitor de Machado é surpreendido com a revelação. Colocar em um mesmo nível da narrativa uma cadelinha e vários tipos de mulher configura a verve irônica do nosso autor-narrador.

Ao longo do conto, várias passagens marcam a ironia machadiana através de suas conversas com o leitor. Neste conto, pertencente à fase inicial da ficção machadiana, a característica mais marcante da ironia está justamente nas intervenções do autor-narrador direcionadas ao seu leitor-narratário, suspendendo em diversos momentos a aura ficcional do texto. 
Seguem-se, portanto, ao longo dos capítulos, trechos como "O leitor superficial conclui daqui que o nosso Mendonça era um homem excêntrico. Não era." (1997, p. 28), ou, ainda, como

Um dia, conversando com uns amigos, [Mendonça] afirmava que se alguma vez encontrasse um par de olhos verdes, fugiria deles com terror.

- Por quê? perguntou-lhe um dos circunstantes admirado.

- A cor verde é a cor do mar, respondeu Mendonça; evito as tempestades de um; evitarei as tempestades dos outros.

Eu deixo ao critério do leitor esta singularidade de Mendonça, que de mais a mais é preciosa, no sentido de Molière. (1997, p. 31)

No trecho acima ainda temos outra característica típica da ironia literária, a intertextualidade, manifesta sob a forma de alusão a Molière. Adiante, as digressões machadianas, cujo alvo principal é seu leitor, marcam o texto, demonstrando que "desconstruir" a aura de ficcionalidade da obra é parte fundamental do procedimento irônico em literatura:

Algum leitor grave achará pueril esta circunstância dos olhos verdes e esta controvérsia sobre a qualidade provável deles. Provará com isso que tem pouca prática do mundo. Os almanaques pitorescos citam até à saciedade mil excentricidades e senões dos grandes varões que a humanidade admira, já por instruídos nas letras, já por valentes nas armas; e nem por isso deixamos de admirar esses mesmos varões. Não queira o leitor abrir uma exceção só para encaixar nela o nosso doutor. Aceitamo-lo com os seus ridículos; quem os não tem? O ridículo é uma espécie de lastro da alma quando ela entra no mar da vida; algumas fazem toda a navegação sem outra espécie de carregamento. (1997, p. 32).

A metáfora do ridículo como "lastro da alma” também realça a tonalidade irônica do discurso, além de representar outra característica tipicamente machadiana, a crença de que há certos aspectos, como o ridículo, inerentes à natureza humana ${ }^{4}$.

\footnotetext{
${ }^{4}$ É o caso do enredo de O Alienista, em que todas as características do ser humano - vícios e virtudes - , quando exageradas, eram indícios de loucura. Sendo assim, a loucura era considerada parte integrante da natureza humana.
} 
Alcançando o final do conto, outra faceta da ironia literária se revela: a Miss Dollar do título resume-se apenas a ele e ao final, quando, narrada brevemente sua morte, figura como inscrição na sua lápide - A Miss Dollar. Esta parece ser uma tônica dos contos de Machado de Assis: títulos que escondem a verdadeira história narrada, que dão a falsa impressão de que a narrativa tratará de tal assunto, quando o assunto verdadeiro é outro, diverso.

\section{Concluindo}

A partir dessas constatações, resultado de nosso trabalho de análise, passamos a considerar a ironia como elemento característico de toda a produção literária de Machado de Assis, seja de qual fase/época for, seja a qual gênero pertença. Isso nos levou a considerar que o Romantismo está permanentemente presente na literatura machadiana, mas não o Romantismo brasileiro, o qual foi aqui aclimatado de maneira a soar como caracterização pejorativa em relação a manifestações artísticas de outras épocas. O Romantismo presente ativamente na obra de Machado de Assis é o herdado do movimento filosófico-literário que foi o Romantismo europeu, em cujas características principais estava o fato de ter trazido o conceito de ironia para a configuração literária, tanto de produção quanto de crítica.

$\mathrm{Na}$ literatura européia, a presença da ironia indicava, com muita clareza e certeza, que uma obra pertencia ao movimento romântico. No Brasil, tal presença, na obra machadiana, nunca indicou sua filiação à escola romântica, muito antes pelo contrário. Aqui, negou-se sempre que Machado pudesse ter escrito obras com qualidade no período inicial, identificado com a escola romântica; suas melhores obras, as que o alçaram à condição de maior nome de nossas letras, sempre foram aquelas referentes ao período maduro, filiado à escola realista.

Logo, a modernidade da obra machadiana, reconhecida por críticos os mais diversos, deve-se, para nós, ao fato de Machado de Assis ter empregado, em toda a extensão de sua obra, o procedimento irônico, herdado da ironia romântica estabelecida como parte da literatura e de sua crítica pelos românticos europeus, para estruturar e estilizar sua obra de maneira tão inovadora e original em nossa literatura. A grande "virada" que representa a literatura "madura" de Machado no panorama da literatura brasileira - a partir das Memórias Póstumas de Brás Cubas (1881) e dos contos constantes da coletânea Papéis Avulsos （1882) -, para nós, já vinha sendo delineada 
desde seus primeiros escritos, inclusive não-ficcionais, como as crônicas publicadas em jornais da época.

Este trabalho pretende ter acrescentado algo à enorme lista de estudos machadianos, no sentido de termos direcionado nossa análise para um aspecto pouco estudado da obra de Machado de Assis. Muito se fala da tradicional, característica e peculiar ironia machadiana, mas pouco se tem debruçado sobre o texto machadiano para encontrar suas formas de manifestação e seu significado, no âmbito do texto literário, como instrumento de veiculação de sentidos e significados outros, que não o estritamente expresso pelas palavras empregadas.

\section{Referências Bibliográficas}

BEHLER, Ernst. Ironie et Modernité. Paris: PUF, 1997.

BOSI, Alfredo. História Concisa da Literatura Brasileira. São Paulo: Cultrix, 1974.

CÂNDIDO, Antônio. Formação da Literatura Brasileira. Belo Horizonte \& Rio de Janeiro: Ed. Itatiaia Ltda., 1997, vol. 1 e 2.

CHIAMPI, Irlemar. Fundadores da Modernidade. São Paulo: Ática, 1991

COUTINHO, Afrânio. A literatura no Brasil, volume 3. Rio de Janeiro: Ed. Sul Americana, 1969.

MACHADO DE ASSIS, Joaquim Maria. Obra Completa. Rio de Janeiro: Nova Aguillar, 1997, 3 vol.

MERQUIOR, José Guilherme. De Anchieta a Euclides: breve história da Literatura Brasileira I. Rio de Janeiro: Topbooks, 1996.

MIGUEL-PEREIRA, Lúcia. História da Literatura Brasileira volume XXII - Prosa de Ficção (de 1870 a 1920). São Paulo: Livraria José Olympio Editora, 1950.

SODRÉ, Nélson Werneck. História da Literatura Brasileira. Rio de Janeiro: Graphia, 2002.

VERÍSSIMO, José. História da Literatura Brasileira: de Bento Teixeira (1601) a Machado de Assis (1908). Brasília: Ed. Universidade de Brasília, 1981. 
